\title{
Study of flow stress and spall strength of additively manufactured Ti-6-4 alloy
}

\author{
Vitaly Paris ${ }^{1, *}$, Amitai Cohen ${ }^{1}$, Eli Gudinetsky ${ }^{2}$, Refael Hevroni ${ }^{1}$, Shmuel Samuha ${ }^{3}$, Shmuel Osovsky ${ }^{4}$,Eitan Tiferet $^{3,5}$, \\ Arnon Yosef-Hai ${ }^{1}$ \\ ${ }^{1}$ NRCN, Physics Department, Beer-Sheva, Israel \\ ${ }^{2}$ IAEC, Yavne, Israel \\ ${ }^{3}$ NRCN, Materials Department, Beer-Sheva, Israel \\ ${ }^{4}$ Technion, Faculty of Mechanical Engineering, Haifa, Israel \\ ${ }^{5}$ ROTEM industries LTD, Additive manufacturing R\&D Center, Rotem, Israel
}

\begin{abstract}
The use of additive manufacturing (AM) by Electron Beam Melting (EBM) or Selective Laser Melting (SLM) has extensively grown in the past few years. A major goal in AM is to manufacture materials with mechanical properties at least as good as traditionally manufactured materials. In this work we present the results of planar impact tests and Split Hopkinson Pressure Bar tests (SHPB) on Ti-6Al-4V manufactured by EBM and LSM techniques. Stress strain curves based on SHPB measurements at strain rate of about $1500 \mathrm{~s}^{-1}$ display similar plastic flow stresses for SLM and EBM processed Ti-6Al-4V alloys, and about $15 \%$ higher than reported for commercial Ti-6Al-4V alloy. Results of planar impact tests on SLM samples display slightly higher spall strength than EBM while the stress at Hugoniot elastic limit (HEL) is practically the same. Hugoniot elastic limit and spall strength estimates for EBM- and SLM-processed Ti$6 \mathrm{Al}-4 \mathrm{~V}$ alloys are at least as high as values obtained for conventionally-processed alloys. The results of post mortem SEM analysis of the spall fracture have demonstrated significant differences in the spall fracture characteristics between the AM-processed and commercial Ti-6Al-4V alloys.
\end{abstract}

\section{Introduction}

The use of AM print-like technique in manufacturing of metal components increased considerably in last ten years $[1,2]$. This trend is driven by the fact that almost nearly any complex geometry can be processed from a $3 \mathrm{D}$ computer modelling using the $3 \mathrm{D}$ - printing or $\mathrm{AM}$ [3]. The AM process refers to a fabrication technique in which three-dimensional objects are obtained by layers synthesizing using SLM or EBM [4]. The basic principle of AM is based on a rapid solidification of a melted prealloyed metal powder for achieving of the desired shape. The temperature differences of the powder bed in SLM compared to EBM affect the solidification rate and the directional growth, which eventually affects the mechanical properties of the material. Although AM products reach their true density values $(99.5 \%$ or higher), micro-poresldefects that might appear during rapid solidification may affect the mechanical behaviour, especially the ductility and fracture properties [2].

The titanium alloy Ti-6Al-4V belongs to the group of metallic alloys (stainless steel, AlSi10Mg, etc. [5, 6]) well suited to AM technologies. Ti-6Al-4V alloy is an attractive, lightweight material widely used for manufacturing aircraft and spacecraft components $[3,7]$ as well as human body implants. Static mechanical properties and fatigue resistance properties of SLM and
EBM-fabricated Ti-6Al-4V alloy have been widely studied [8]. Possible application of AM-manufactured Ti-6Al-4V components under extreme conditions and particularly under high strain rate loading requires knowledge of corresponding strength and failure properties.

The current study focuses on dynamic mechanical characterization of Ti-6Al-4V alloy manufactured by SLM and EBM techniques, while samples from conventionally processed $\mathrm{Ti}-6 \mathrm{Al}-4 \mathrm{~V}$ rod were used for comparison. In order to characterize the dynamic strength and fracture properties of $\mathrm{AM} \mathrm{Ti}-6 \mathrm{Al}-4 \mathrm{~V}$, compressive Hopkinson bar and planar impact experiments with a light gas gun were carried out. The current study results demonstrate that at strain rates of about $1500 \mathrm{~s}^{-1}$ the AM-manufactured alloys have about $15 \%$ higher flow stress compared to conventionallyprocessed alloy. As apparent from planar impact experiments the HEL and the dynamic yield stress of AM-manufactured alloys exceeds only slightly the values of the commercial alloy. The measured spall strength is practically the same for EBM, SLM and conventionally-processed Ti-6Al-4V alloy.

*Corresponding author: vitalyp@nren.gov.il 


\section{Materials and Experimental Methods}

The selected material used for this research was an extralow interstitial grade of Ti-6Al-4V alloy. The average particle diameter of the powder was of $30 \mu \mathrm{m}$. In case of the laser source energy, a laser with a power of 250 Watts and $1000 \mathrm{~nm}$ in wavelength was used with continuous mode according to the zigzag pattern which was rotated $90^{\circ}$ between each layer. The temperature of the metal build platform was $30^{\circ} \mathrm{C}$. At each build cycle a $30 \mu \mathrm{m}$ layer of the alloy powder is being spread on the platform and melted by the laser. This process was repeated until the specimen size was achieved. Stress relieving of $2 \mathrm{hr}$. was applied at $350{ }^{\circ} \mathrm{C}$. In the case of EBM energy source, a power of $1 \mathrm{KW}$ was used with a zigzag scan strategy in the $\mathrm{Z}$ direction with pre-sintering temperature of $700{ }^{\circ} \mathrm{C}$ before melting. Microstructure of the representing samples of EBM and SLM-processed alloys was evaluated using scanning electron microscopy and is shown in Fig. 1. The average values of density and sound velocities are given in Table 1 .

Table 1. Density and sound velocities of AM Ti-6Al-4V alloys studied in the present work.

\begin{tabular}{|c|c|c|c|c|}
\hline & $\begin{array}{c}\text { Density } \\
{\left[\mathrm{g} / \mathrm{cm}^{3}\right]}\end{array}$ & $\begin{array}{c}\mathrm{C}_{\mathrm{L}}, \\
\mathrm{km} / \mathrm{s}\end{array}$ & $\mathrm{C}_{\mathrm{s}}, \mathrm{km} / \mathrm{s}$ & $\mathrm{C}_{\mathrm{b}}, \mathrm{km} / \mathrm{s}$ \\
\hline $\mathrm{EBM}$ & 4.403 & 6.185 & 3.204 & 4.956 \\
\hline $\mathrm{SLM}$ & 4.420 & 6.221 & 3.236 & 4.974 \\
\hline $\begin{array}{c}\text { Convent. } \\
\text { rod }\end{array}$ & 4.416 & 6.145 & 3.156 & 4.948 \\
\hline
\end{tabular}

Two types of specimens were machined from the AM-grown rods: cylindrical specimens $(6-\mathrm{mm}$ diameter and 6-mm long) were machined for the SHPB experiments. For planar impact experiments, square specimens $12 \times 12 \mathrm{~mm}$ and 2-mm thick were machined.

The experiments were conducted in the Laboratory for Dynamic Properties of Materials at NRCN. In the first set of experiments standard cylindrical Ti-6Al-4V samples were placed between the 1-inch in diameter incident and transmitted bars of a standard Split Hopkinson Pressure Bar (SHPB) system. The velocity of the bars $v(t)$ was recorded using Photon Doppler Velocimeter (PDV) system adapted for very low velocity measurements [9]. The elastic strains in the bars $\varepsilon(t)$ are related to the bar's velocity $v(t)$ through,

$$
\varepsilon(t)=v(t) / C
$$

where $C$ is the longitudinal speed of sound in the bar.

In the second set of experiments $12 \times 12 \mathrm{~mm}$ square and 2-mm thick Ti-6Al-4V samples were shock loaded with $0.5-\mathrm{mm}$ thick $\mathrm{Cu}$ impactors using a $25-\mathrm{mm}$ bore light gas gun. The velocities of the impactors were measured by blocking a set of 2 laser rays spaced at a known distance. The free surface velocity of the samples was continuously monitored using a Velocity Interferometer System for Any Reflector (VISAR) [10]. The samples were recovered, sectioned and analyzed post mortem using Scanning Electron Microscope (SEM) focusing on the spalling region.
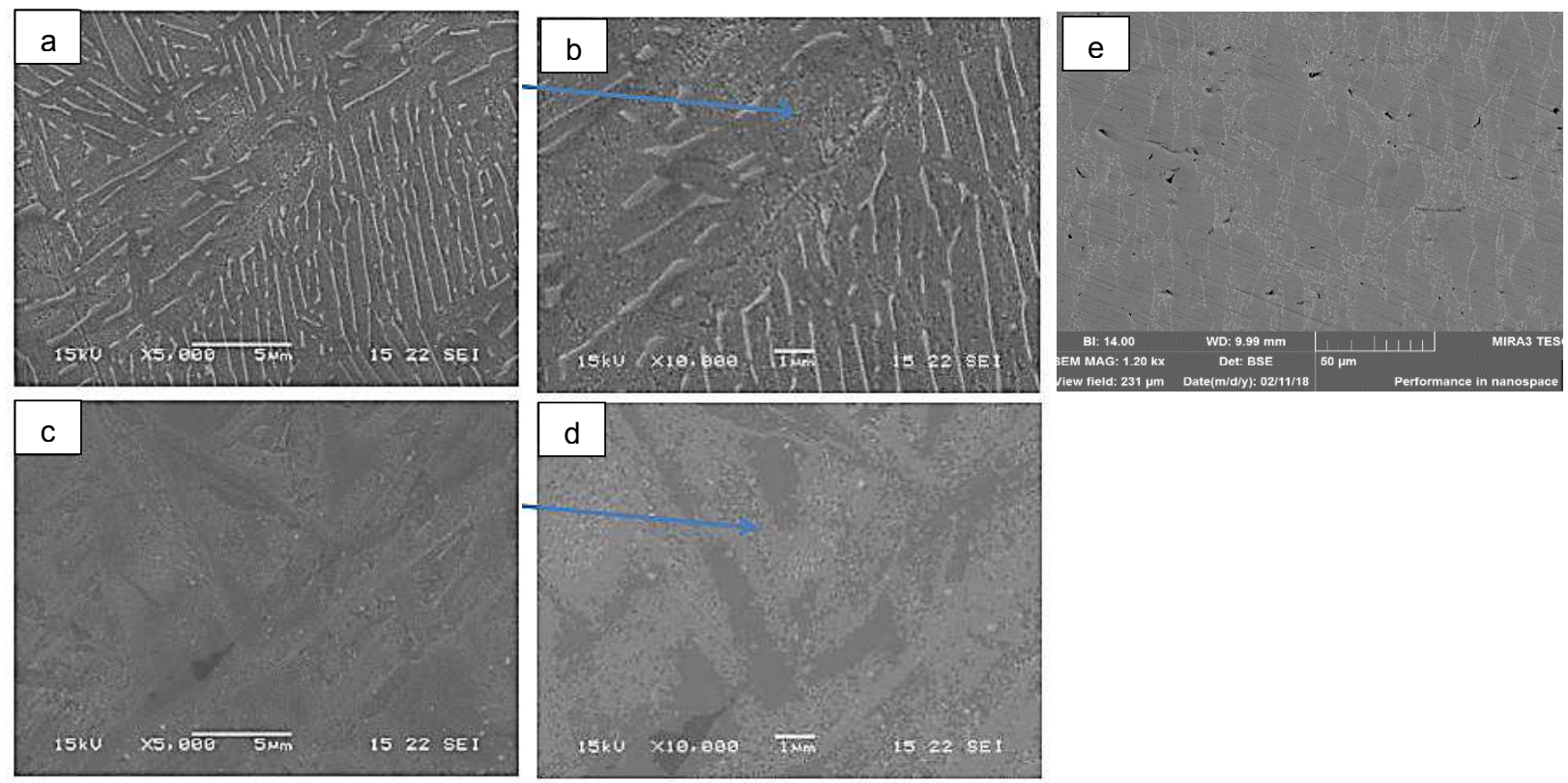

Fig. 1. Scanning electron micrographs of Ti-6Al-4V samples processed by EBM (a, b), SLM (c, d) and samples from conventionally processed rod (e). The arrows are pointing on typical white dots arising from surface, which are recognized as submicron acicular grains. 


\section{Results}

True stress- true strain curves obtained after a standard analysis of the raw data of the SHPB experiments with EBM and conventionally processed Ti-6Al-4V samples are shown in Figure 2. The stress-strain curve for SLM processed Ti-6Al-4V is provided for comparison [11]. The obtained results demonstrate that additively manufactured Ti-6Al-4V alloys possess about $15-20 \%$ higher flow stress than the conventionally manufactured alloy does.

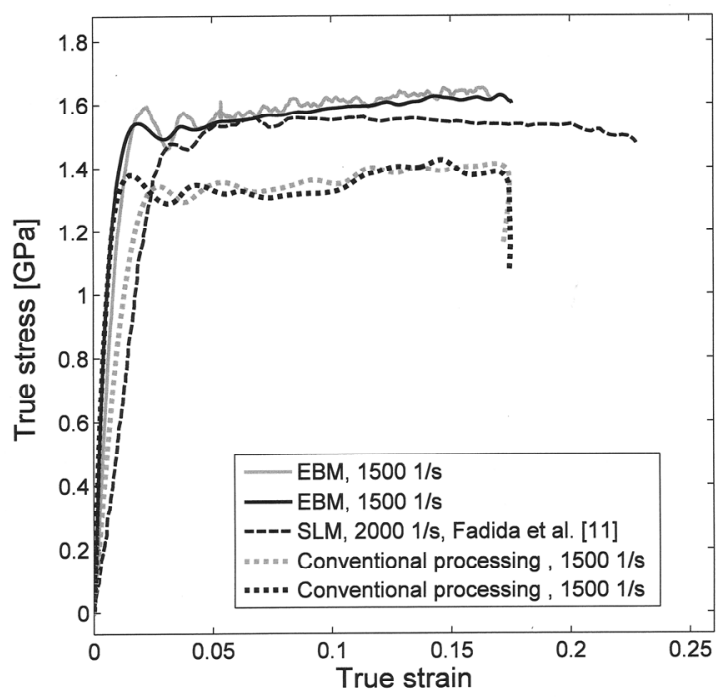

Fig. 2. True stress- true strain curves obtained with EBM and conventionally processed Ti-6-4 samples. The stress-strain data for SLM-processed alloy from Fadida et al. [11] is shown for comparison.

Free surface velocity profiles recorded in planar impact experiments with 2-mm thick specimens of the three types of Ti-6Al-4V (conventionally processed,
EBM and SLM) are shown in Fig. 3. The velocity histories of all three materials contain an elastic precursor wave having the amplitude $u_{\mathrm{HEL}}$ of about 200 $\mathrm{m} / \mathrm{s}$. The stress behind the elastic precursor wave $\sigma_{\mathrm{HEL}}$ can be calculated using the equation 2 :

$$
\sigma_{\mathrm{HEL}}=1 / 2 \rho_{0} C_{\mathrm{L}} u_{\mathrm{HEL}}
$$

where $\rho_{0}$ is initial density of the sample, $C_{\mathrm{L}}$ is longitudinal sound velocity. The dynamic yield stress at HEL, $Y_{\mathrm{D} 0}$ may be estimated as:

$$
Y_{\mathrm{D} 0}=(1-v) /(1-2 v) \sigma_{\mathrm{HEL}}
$$

where $v$ is Poisson's ratio. Values of $\sigma_{\mathrm{HEL}}$ and $Y_{\mathrm{D} 0}$ obtained in the planar impact experiments with Ti-6Al$4 \mathrm{~V}$ alloys are presented in Table 2 . The calculated values of stress at HEL, $\sigma_{\mathrm{HEL}}$ and consequently, of dynamic yield stress, $Y_{\mathrm{D} 0}$ based on low velocity experiments for EBM and SLM processed alloy are about 8-9\% higher compared to the conventional alloy. However, at higher impact velocity all three alloys exhibit very similar $Y_{\mathrm{D} 0}$ values. Recall that according to SHPB experiments, the AM alloy exhibits about $15 \%$ higher flow stress compared to conventionally-processed alloy.

The elastic precursor waves (Fig. 3) are followed by a ramp velocity rise associated with the strain hardening of the material which in turn followed by a plastic shock wave. Shock waves arriving at the free surface of the target and impactor are reflected as rarefaction waves (arrival of the rarefaction wave to a free surface of the sample is manifested as velocity decrease on VISAR profile, so called velocity pullback). As result of the interaction of rarefaction waves, tensile stress is generated inside the target.
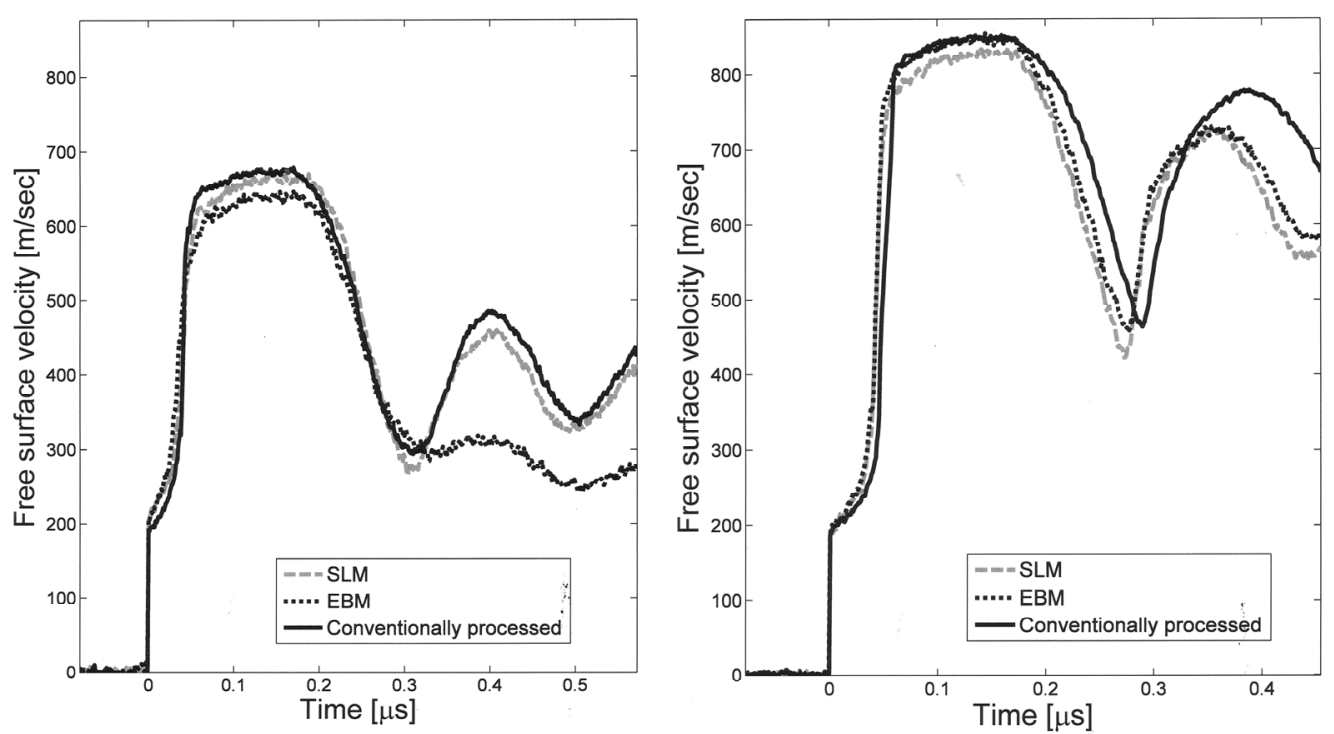

Fig. 3. Free surface velocity profiles recorded in planar impact tests with of Ti-6-4 samples processed by EBM, SLM and reference samples. The profiles are divided in two groups: low impact velocity shots $(\sim 560 \mathrm{~m} / \mathrm{sec}$, left $)$ and higher impact velocity shots $(\sim 710$ $\mathrm{m} / \mathrm{sec}$, right). 
Table 2. Details and results of planar impact tests.

\begin{tabular}{|c|c|c|c|c|c|c|c|c|c|c|}
\hline Test \# & Material & $\begin{array}{c}\text { Target } \\
\text { thick., } \\
\mathrm{mm}\end{array}$ & $\begin{array}{c}\text { Imp. } \\
\text { thick., } \\
\mathrm{mm}\end{array}$ & $\begin{array}{c}\text { Imp. } \\
\text { Vel., } \\
\mathrm{km} / \mathrm{s}\end{array}$ & $\begin{array}{c}\sigma_{\mathrm{HEL}}, \\
\mathrm{GPa}\end{array}$ & $\begin{array}{c}Y_{\mathrm{D} 0,}, \\
\mathrm{GPa}\end{array}$ & $\begin{array}{c}u_{\mathrm{pb}}, \\
\mathrm{km} / \mathrm{s}\end{array}$ & $\begin{array}{c}h_{\mathrm{sp}}, \\
\mathrm{mm}\end{array}$ & $\begin{array}{c}\sigma_{\mathrm{sp}}, \\
\mathrm{GPa}\end{array}$ & $\begin{array}{c}\text { Strain } \\
\text { rate, } \mathrm{s}^{-1}\end{array}$ \\
\hline 1 & Conven. & 1.90 & 0.51 & 0.574 & 2.58 & 1.43 & 0.382 & 0.55 & 4.6 & $4.0 \cdot 10^{5}$ \\
\hline 2 & SLM & 1.84 & 0.51 & 0.566 & 2.83 & 1.53 & 0.389 & 0.55 & 4.8 & $4.7 \cdot 10^{5}$ \\
\hline 3 & EBM & 1.82 & 0.53 & 0.552 & 2.80 & 1.51 & 0.347 & 0.55 & 4.2 & $4.0 \cdot 10^{5}$ \\
\hline 4 & Conven. & 2.11 & 0.50 & 0.705 & 2.58 & 1.43 & 0.385 & 0.55 & 4.9 & $4.6 \cdot 10^{5}$ \\
\hline 5 & SLM & 1.89 & 0.48 & 0.701 & 2.61 & 1.41 & 0.405 & 0.55 & 5.2 & $4.8 \cdot 10^{5}$ \\
\hline 6 & EBM & 1.85 & 0.47 & 0.717 & 2.59 & 1.40 & 0.389 & 0.55 & 5.0 & $4.3 \cdot 10^{5}$ \\
\hline
\end{tabular}

If the tensile stress exceeds the spall strength of the material, the spall fracture forms and a spall signal is generated. Arrival of the spall signal is indicated by a velocity rise on the VISAR waveform.

All the velocity waveforms shown on Fig. 3 except to the EBM test at low impact velocity contain velocity rise indicative of a spall fracture. The waveform of EBM test (\#3 in table 2) has very small velocity rise after velocity pullback, which may be a manifestation of incipient spall. The spall strength of the material in the present work was estimated as in [12]:

$$
\sigma_{\mathrm{sp}}=1 / 2 \rho_{0} C_{\mathrm{b}}\left(u_{\mathrm{pb}}+\delta\right)
$$

where $\rho_{0}$ is initial density of the sample, $C_{\mathrm{b}}$ is bulk sound velocity, $u_{\mathrm{pb}}$ is velocity pullback amplitude and $\delta$ velocity correction which is estimated as:

$$
\delta=\left(h_{s p} / C_{b}-h_{s p} / C_{L}\right)\left|\dot{u}_{1} \dot{u}_{2}\right| /\left(\left|\dot{u}_{1}\right|-\dot{u}_{2}\right)
$$

where $h_{\text {sp }}$ is spall plate thickness, $\dot{u}_{1}$ and $\dot{u}_{2}$ are the slopes of pullback and spall signal parts of VISAR waveforms, respectively. The obtained values of spall strength as well as other details of planar impact experiments are summarized in table 2 . The spall strength values $\sigma_{\mathrm{sp}}$
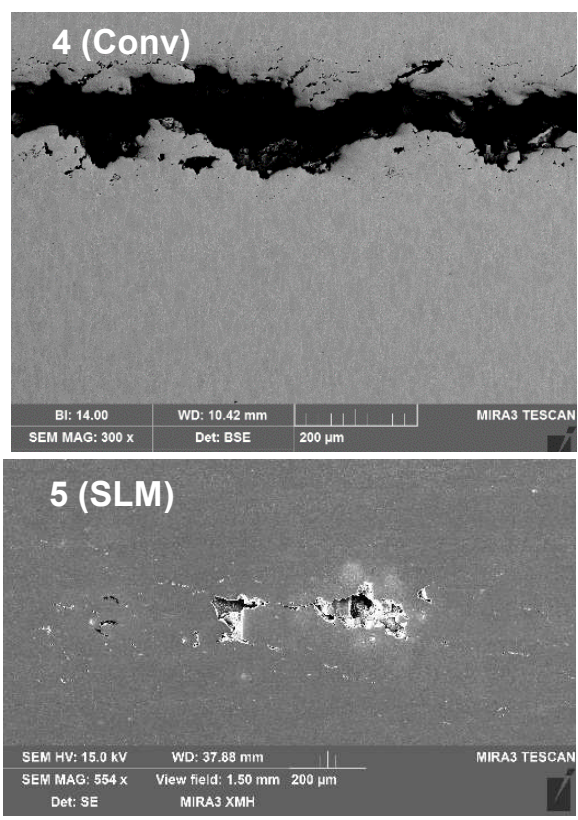

obtained in experiments 4-6 (impact velocity $\sim 710 \mathrm{~m} / \mathrm{s}$ ) are practically the same for all three alloys, about $5 \mathrm{GPa}$. The spall strength values $\sigma_{\mathrm{sp}}$ obtained in experiments 1-3 (impact velocity $\sim 560 \mathrm{~m} / \mathrm{s}$ ) are 4.8 and $4.6 \mathrm{GPa}$ for SLM and conventional alloys, respectively. The lower value of spall strength $(\sim 4.2 \mathrm{GPa})$ for EBM processed alloy is consistent with previously mentioned negligibly small spall signal magnitude in this experiment (Fig. 3).

Scanning electron micrographs of sectioned targets after high-velocity experiments 4 and 5 (Fig. 4) demonstrate distinct differences in the spall fracture behaviour of SLM-processed and conventional alloys. While the micrograph of the mid-section of conventional alloy target contains fully-developed fracture surface (\#4 right), the target of SLM-processed alloy has developed only partially coalesced arrays of large voids and microcracks. This may be attributed to significantly finer microstructure of the SLM alloy compared to conventional alloy (see Fig. 1). However, the observed differences are in contradiction with the fact, that the spall strength in these experiments is practically the same. Further investigation is needed to understand the mechanisms behind these differences in the fracture behaviour.
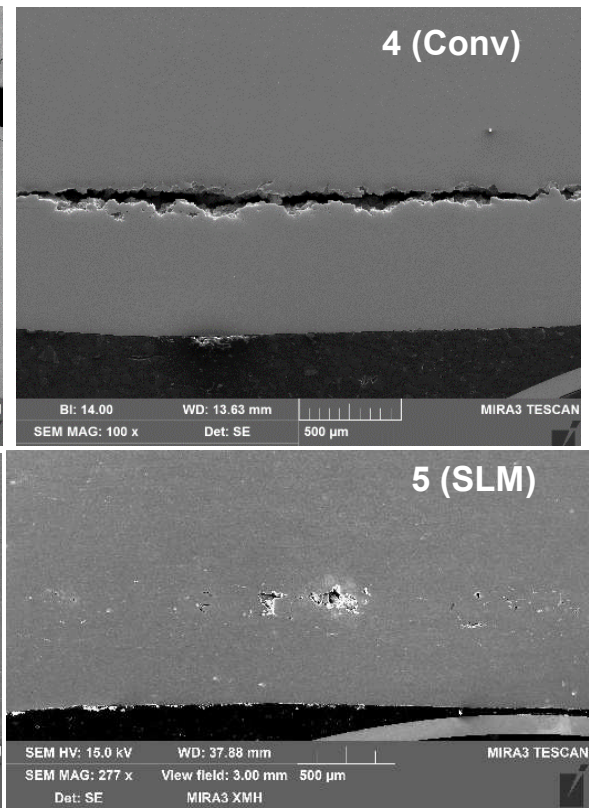

Fig. 4. Scanning electron micrographs of sectioned SLM (\#5) and conventionally processed (\#4) Ti-6Al-4V targets after highvelocity shots. 

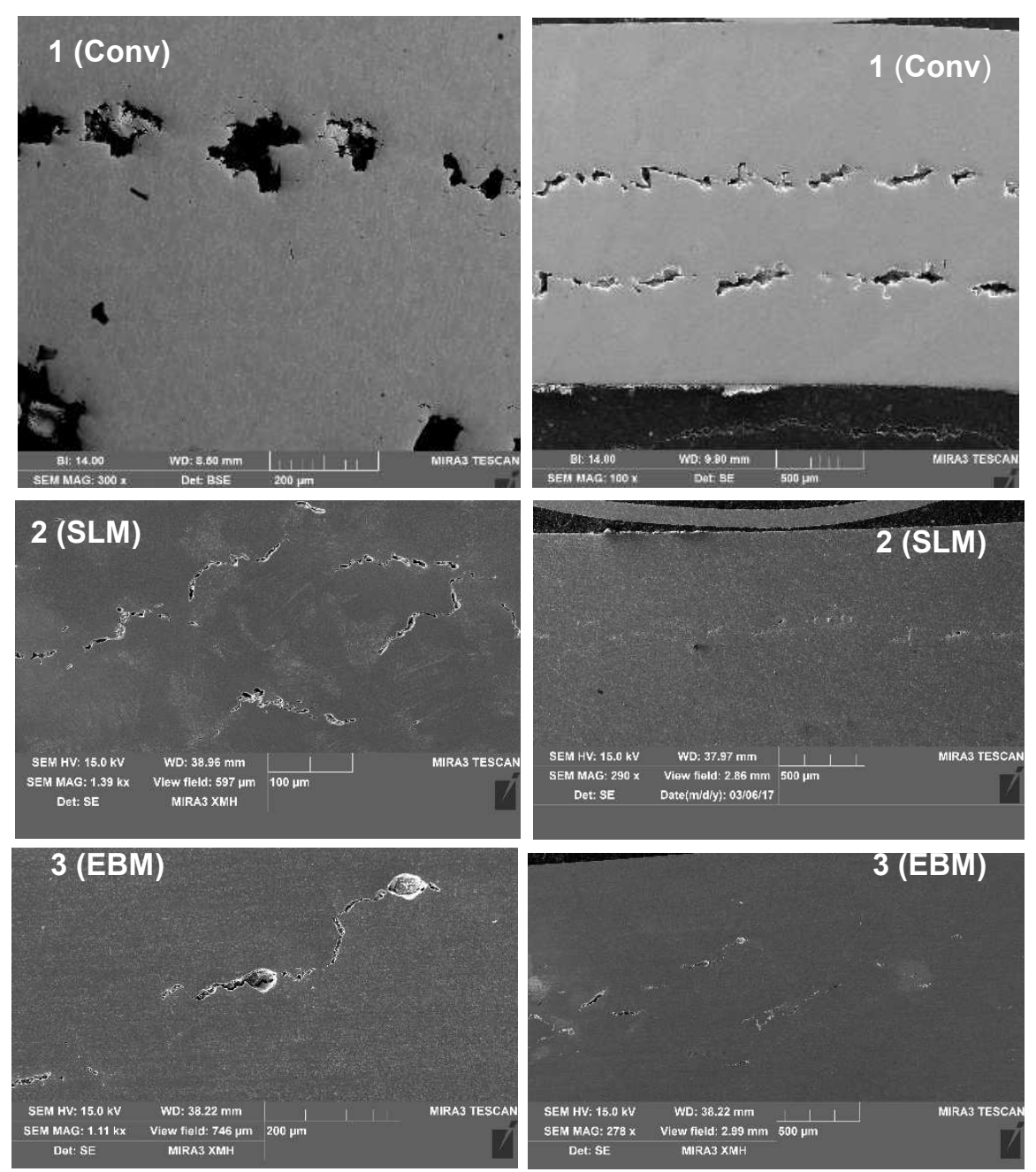

Fig. 5. Scanning electron micrographs of sectioned EBM (\#3) and SLM- processed (\#2) Ti-6Al-4V targets and back-scattered electron micrographs of targets made of conventionally-processed Ti-6Al-4V rod (\#1) after low-velocity shots.

Figure 5 shows scanning electron micrographs of sectioned EBM (\#3) and SLM-processed (\#2) as well as of conventionally processed Ti-6Al-4V targets (\#1) recovered after low velocity shots. The micro-voids and micro-cracks patterns of two AM targets (\#2 and \#3) shown on the right-hand images at Fig. 5 (reference scale length $500 \mu \mathrm{m}$ ) are slightly different. The crack pattern of SLM target forms localized array while the crack pattern of EBM target is much more spatially scattered.

The back-scattered electron micrographs of conventionally- processed $\mathrm{Ti}-6 \mathrm{Al}-4 \mathrm{~V}$ target recovered after low velocity shot (\#1) demonstrate two spall fracture planes: one at about $0.55 \mathrm{~mm}$ from the free back surface as predicted by the calculations and another one at about $1.1 \mathrm{~mm}$ from the free back surface. Although the two spall fracture planes are not fully developed, the observed voids density and average voids size are much larger compared to AM-processed (EBM and SLM) alloys.

\section{Conclusions}

Results of SHPB experiments indicate about $15 \%$ higher flow stress for EBM-processed titanium alloy compared to conventionally processed alloy. Hugoniot elastic limit and dynamic yield strength estimates for EBM and SLM-processed Ti-6Al-4V alloys are at least as high as values obtained for conventionally-processed alloys. AM-processed alloys exhibit practically the same spall strength as conventionally-processed reference alloy. In contradiction to this, the SEM-based spall fracture characteristics of the conventional and AM Ti-6Al-4V targets differ significantly. Further investigation is needed to understand the mechanisms behind these differences. No spall signal was observed in experiment \#3 (EBM), and this fact agrees with a low spall strength calculated for this experiment and a very small pores/cracks density, as seen in the SEM micrograph \#3 in Fig. 5.

\section{References}

1. S. Sing, J. An, W. Yeong, F. Wiria, J. Orthop. Res., 34(3), 369-385 (2016)

2. L. Murr, S. Gaytan, D. Ramirez, E. Martinez, J. Hernandez, K. Amato, R. Wicker, J. Mat. Sci. Tech., 28(1), 1-14 (2012) 
3. S. Rawal, J. Brantley, N. Karabudak, in 6th International Conference on Recent Advances in Space Technologies (RAST) (2013)

4. E. Merriam, J. Jones, L. Howell, Design of 3DPrinted Titanium Compliant Mechanisms. (2014)

5. G. T. Gray III, V. Livescu, P. A. Rigg, C. P. Trujillo, C.M. Cady, S.R. Chen, J.S. Carpenter, T. J. Lienert, S. Fensin, EPJ Web of Conferences 94, 02006 (2015)

6. E. Frasier, Metal additive manufacturing: a review, J. Mater. Eng. Perform. 23, 1917-1928 (2014)

7. B. Baufeld, O. Van der Biest, R. Gault, Mat. Desn. 31, 106-111 (2010)
8. R. Carmi, E. Tiferet, E. Chakotay, I. Alon, G. Guttmann, R. Sneck, A. Busiba (proceedings of International Acoustic Emmision Conference, 2017)

9. C. Avinadav, Y. Ashuach, R. Kreif, Rev. Sci. Instrum. 82, 073908 (2011)

10. L. M. Barker, R. E. Hollenbach, J. Appl. Phys. 43 4669 (1972)

11. R. Fadida, D. Rittel, A. Shirizly, J. Appl. Mech. 82, 041004 (2015)

12. G. I. Kanel, S. V. Rasorenov, V. E. Fortov, Academy of Sciences USSR-Doklady, 275(2), 269271(1984) 